\title{
PENINGKATAN PENGETAHUAN KONSEPTUAL SISWA DENGAN MENGGUNAKAN MODEL PROBLEM BASED LEARNING
}

\author{
Oleh: \\ Ika Trisni Simangunsong ${ }^{1)}$ \\ Dede Parsaoran Damanik ${ }^{2}$ \\ dan Jelita Panjaitan ${ }^{3)}$ \\ Universitas Darma Agung, Medan 1,2,3) \\ E-mail: \\ ikatrisnisimangunsong@gmail.com ${ }^{1)}$ \\ dedeparsaoran@gmail.com ${ }^{2)}$ \\ dan jelitapanjaitan3@gmail.com ${ }^{3)}$
}

\begin{abstract}
This study aims at determining the students' conceptual knowledge improvement in using the Problem Based Learning model. This study is quasi-experimental with the design of the pretest-posttest group, in which the population is the tenth grade students of Yapim Taruna High School. The instrument in this study is in the form of essays that had been tested for validity, reliability, level of difficulty and different power. The results of this study show an improvement of students' conceptual knowledge in the experimental class by using a model of problem based learning is better than the control class.

Keywords: Problem Based Learning, Conceptual Knowledge
\end{abstract}

\begin{abstract}
ABSTRAK
Penelitian ini bertujuan untuk mengetahui peningkatan pengetahuan konseptual siswa menggunakan model Problem Based Learning. Desain penelitian ini kuasi eksperimen dengan desain kelompok pretes-postes, yang populasinya adalah siswa kelas X SMA Yapim Taruna. Instrumen dalam penelitian ini berbentuk essay yang telah diuji validitas, reliabilitas, tingkat kesukaran dan daya beda. Hasil penelitian ini menunjukkan peningkatan pengetahuan konseptual siswa pada kelas eksperimen dengan menggunakan model problem based learning lebih baik dari kelas kontrol.
\end{abstract}

Kata kunci: problem based learning, pengetahuan konseptual

\section{PENDAHULUAN}

Pendidikan adalah suatu proses dalam rangka mempengaruhi siswa agar dapat menyesuaikan diri sebaik mungkin terhadap lingkungannya, dengan demikian akan menimbulkan perubahan dalam dirinya yang memungkinkan untuk berfungsi dalam kehidupan masyarakat.. Oleh karena itu, pembaharuan pendidikan harus selalu dilakukan untuk meningkatkan kualitas pendidikan nasional.
Belajar dapat dipandang sebagai proses yang diarahkan kepada tujuan dan proses berbuat melalui pengalaman. Belajar juga merupakan proses melihat, mengamati dan memahami sesuatu. Ketika seorang anak mendapatka hasil tes yang bagus, tidak bisa dikatakan sebagai belajar apabila hasil tesnya itu didapatkan dengan cara yang tidak benar, misalnya mencontek. Belajar dan mengajar merupakan dua konsep yang tidak bisa dipisahkan satu sama lain. Belajar 
menunjukkan apa yang harus dilakukan seseorang sebagai subjek menerima (sasaran didik), sedangkan mengajar menunjukkan apa yang harus dilakukan oleh guru sebagai pengajar. Mengajar pada dasarnya merupakan suatu usaha untuk menciptakan kondisi atau sistem lingkungan yang mendukung dan memungkinkan untuk berlangsungnya proses belajar. Walaupun belajar mengajar merupakan kegiatan yang berbeda satu dengan yang lainnya, namun kedua jenis kegiatan tersebut merupakan satu kesatuan yang searah dan sejalan terutama dalam tujuan pencapaian hasil pembelajaran.

Pada umumnya pelajaran fisika sangat sulit diterima oleh siswa karena mengarah kedalam perhitungan matematika yang dinyatakan dalam rumusrumus sehingga siswa merasa bosan dan jenuh untuk mempelajari pelajaran fisika tersebut. Masalah-masalah diatas menyebabkan hasil belajar fisika yang merupakan pengetahuan konseptual fisika siswa rendah.

\section{TINJAUAN PUSTAKA}

Arends (2008:117) menyatakan bahwa : "Taksonomi yang telah direvisi membagi pengetahuan menjadi empat kategori: 1). pengetahuan faktual termasuk elemen-elemen dasar yang perlu diketahui siswa yang akan dipelajari sebuah topik. 2). Pengetahuan konseptual adalah pengetahuan entang saling keterkaitan di antara elemen-elemen dasar. 3). Pengetahuan procedural adalah mengetahui cara mengerjakan sesuatu. 4). Pengetahuan metakognitif adalah pengetahuan tentang kognisi siswa sendiri dan pengetahuan tentang kapan pengetahuan konseptual atau procedural tertentu".

Hilbert dalam penelitian Samsar Rivai (2015:6) menyatakan bahwa : "Pengetahuan konseptual dapat diartikan secara jelas sebagai pengetahuan yang kaya dalam hubungan-hubungan. Hal ini dapat dianggap sebagai suatu jaringan pengetahuan yang menghubungkan penggalan-penggalan informasi yang telah tersimpan di dalam memori atau antara suatu penggalan pengetahuan yang telah ada dengan yang baru dipelajari.Suatu informasi menjadi pengetahuan konseptual hanya jika informasi tersebut terintegrasi ke dalam suatu jaringan yang lebih luas yang sudah ada dalam benak anak sebelumnya.Pengetahuan konseptual mengacu kepada pengetahuan yang mendasari struktur fisika, dan merupakan keterhubungan atau keterkaitan gagasan yang menjelaskan dan makna pada prosedur fisika.Untuk memahami pengetahuan konseptual dapat dilakukan dengan menggunakan model konkret dan semikonkret".

Kenyataan sehari-hari dalam pembelajaran di sekolah sering terjadi kesalahan-kesalahan saat siswa menyelesaikan soal karena tidak adanya pemahaman siswa terhadap pengetahuan konseptual. Hilbert dalam penelitian Samsar Rivai (2015:6) menyatakan, "Pengetahuan prosedural dibentuk dari dua bagian yang berbeda yang bersusun dari representasi simbol tentang matematika dan algoritma-algoritma atau aturan-aturan untuk menyelesaikan tugas-tugas matematika". Para siswa tidak sepenuhnya terkompoten dalam matematika jika sudah satu jenis dari pengetahuan konseptual dan procedural kurang sempurna atau keduanya telah dicapai tetapi masih merupakan entitas-entitas yang terpisah. Jika prosedur-prosedur tidak dihubungkan, para siswa mungkin mempunyai perasaan intuitif yang bagus terhadap matematika, tetapi tidak memecahkan permasalahan, atu mereka mungkin menghasilkan jawaban-jawaban tetapi tidak memahami apa yang sedang mereka kerjakan. Mengkaitkan hubungan antara pengetahuan konseptual dan sistem simbol-simbol. Terlihat bahwa jika siswa belajar dengan menghubungkan pengetahuan konseptual dan prosedural siswa akan memahami makna setiap langkah. Joyce dan Weil (2016:132) yang diterjemahkan olehAchmad Fawaid dan Atteila Mirza menyatakan bahwa : "Kunci 
untuk memahami strategi yang digunakan siswa untuk mencapai suatu konsep adalah menganalisis bagaimana siswa mendekati informasi yang tersedia dalam contohcontoh yang guru sediakan.Khususnya apakah mereka fokus hanya pada aspekaspek informasi tertentu (strategi partistik), atau apakah mereka menggunakan seluruh atau hampir semua informasi itu (strategi holistik). Ada dua cara yang dapat digunakan untuk mengamati dan memperoleh informasi tentang strategi yang digunakan siswa untuk mencapai konsep. Pertama, setelah suatu konsep dicapai, guru dapat meminta siswa menceritakan pemikirannya agar latihan terus berlangsung. Misalnya, dengan menggambarkan gagasan yang siswa munculkan, sifat apa yang mereka fokuskan dan modifikasi apa yang mereka buat. Kedua, guru dapat meminta siswa untuk menuliskan hipotesis mereka".

Anderson dalam Arends (2008:118) menyatakan bahwa : "Pengetahuan konseptual adalah saling keterkaitan diantara elemen-elemen dasar dalam struktur yang lebih besar yang memungkinkan mereka untuk berfungsi bersama. Ada beberapa tipe-tipe utama dalam dimensi pengetahuan konseptual yaitu: 1). Pengetahuan tentang klasifikasi dan kategori, 2). Pengetahuan tentang prinsip dan generalisasi, 3). Pengetahuan tentang teori, model, dan struktur".

Berdasarkan pendapat para ahli di atas, maka bisa disimpulkan bahwa pengetahuan konseptual merupakan pengetahuan yang lebih kompleks dan diorganisasi dari beberapa pengetahuan faktualnya. Pengetahuan konseptual menyatakan hubungan antara pengetahuan faktual berupa unsur-unsur dasar dengan struktur keilmuan yang lebih besar sehingga memungkinkan terjadinya pengetahuan baru.

Prof. Howard Barrows dan Kelson dalam Taufiq Amir (2015:12) menyatakan bahwa : "Problem Based Learning (PBL) adalah kurikulum dan proses pembelajaran. Dalam kurikulumnya, dirancang masalah- masalah yang menuntut siswa mendapatkan pengetahuan yang penting, membuat mereka mahir dalam memecahkan masalah, dan memiliki strategi belajar sendiri serta memiliki kecakapan berpartisipasi dalam tim. Proses pembelajarannya menggunakan pendekatan yang sistemik untuk memecahkan masalah atau menghadapi tantangan yang nanti diperlukan dalam karier dan kehidupan sehari-hari”.

Boud dan Feletti dalam Rusman (2014:230), mengemukakan bahwa "Problem Based Learning adalah inovasi yang paling signifikan dalam pendidikan".Margetson dalam Rusman (2014:230) mengemukakan bahwa : "Kurikulum PBM membantu untuk meningkatkan perkembangan keterampilan belajar sepanjang hayat dalam pola pikir yang terbuka, reflektif, kritis dan belajar aktif. Kurikulum PBM memfasilitasi keberhasilan memecahkan masalah, komunikasi, kerja kelompok dan keterampilan interpersonal dengan lebih baik disbanding pendekatan lain".

Tan, Dkk dalam Taufiq Amir (2015:12) menyatakan bahwa : "Model PBL memiliki ciri-ciri seperti pembelajaran dimulai dengan pemberian masalah, biasanya masalah memiliki konteks dengan dunia nyata, pemelajar secara berkelompok aktif merumuskan masalah dan mengidentifikasi kesenjangan pegetahuan mereka, mempelajari dan mencari sendiri materi yang terkait dengan masalah".

Menurut Rusman (2014:233) studi kasus Problem Based Learning, meliputi : “1). Penyajian masalah; 2). Menggerakkan inquiry; 3). Langkah-langkah PBM, yaitu analisa inisial, mengangkat isu-isu belajar; interaksi kemandirian dan kolaborasi pemecahan masalah, integrasi pengetahuan baru, penyajian solusi dan evaluasi."

Berdasarkan pendapat para ahli tersebut, maka model pembelajaran Problem Based Learning merupakan salah satu model pembelajaran inovatif yang dapat memberikan kondisi belajar aktif 
kepada siswa. Model pembelajaran ini dilakukan dengan adanya pemberian rangsangan berupa masalah-masalah yang kemudian dilakukan pemecahan masalah oleh siswa yang diharapkan dapat menambah keterampilan siswa dalam pencapaian materi pembelajaran.

\section{METODE PELAKSANAAN}

Penelitian ini dilakukan di kelas $\mathrm{X}$ Semester II SMA Yapim Taruna. Populasi dalam penelitian ini adalah seluruh siswa kelas X Semester II Yapim Taruna. Pengambilan sampel penelitian dilakukan secara acak kelas (cluster random sampling). Jenis penelitian yang digunakan adalah Quasi eksperimen. Penelitian ini melibatkan dua kelas yaitu kelas eksperimen dan kelas kontrol dimana kedua kelas ini mendapatkan perlakuan yang berbeda. Kelas eksperimen diberi perlakuan dengan model problem based learning dan kelas kontrol diberi perlakuan dengan model direct instruction. Desain penelitian dapat dilihat pada Tabel 1 dibawah ini :

Tabel 1. Two group pretest-postest design

\begin{tabular}{|l|c|c|c|}
\hline \multicolumn{1}{|c|}{ Kelas } & Pretes & Perlakuan & Postest \\
\hline Eksperimen & $\mathrm{T}_{1}$ & $\mathrm{X} 1$ & $\mathrm{~T}_{2}$ \\
\hline Kontrol & $\mathrm{T}_{1}$ & $\mathrm{X} 2$ & $\mathrm{~T}_{2}$ \\
\hline
\end{tabular}

Keterangan :

$\mathrm{T}_{1}$ : tes kemampuan awal (pretest) untuk kelas eksperimen dan kelas kontrol.

$\mathrm{T}_{2}$ : tes kemampuan akhir (postest) untuk kelas eksperimen dan kelas kontrol.

X1: pembelajaran model problem based learning.

$\mathrm{X} 2$ : pembelajaran model direct instruction.

\section{Instrumen Penelitian}

Instrumen yang digunakan pada penelitian ini adalah tes hasil belajar berupa pengetahuan konseptual siswa yang terdiri dari 15 soal dan berbentuk essay. Untuk mengetahui kevalitan instrumen, validitas tes yang digunakan adalah validitas isi (content validity) yaitu berupa soal-soal untuk mengukur aspek pengetahuan konseptual fisika siswa kelas $\mathrm{X}$ pada materi Alat-alat Optik. Tahaptahap penghitungan koefisien validitas butir soal ini adalah menghitung koefisien validitas suatu butir soal dengan menggunakan rumus teknik korelasi product moment angka kasar sebagai berikut:

$$
\begin{aligned}
& r_{\mathrm{xy}}=\frac{N \sum X Y-(\Sigma X)(\Sigma Y)}{\sqrt{\left(N \Sigma X^{2}-\Sigma(X)^{2}\right\}\left[N \Sigma Y^{2}-\left(\Sigma Y^{2}\right)\right.}} \\
& r_{\mathrm{xy}}=\text { koefisien korelasi } \\
& \mathrm{X}=\text { skor item } \\
& \mathrm{Y}=\text { skor total } \\
& \mathrm{N}=\text { jumlah siswa }
\end{aligned}
$$

Untuk menghitung Reliabilitas Tes bentuk uraian /essay digunakan rumus Alpha dengan persamaan sebagai berikut:

$r_{11}=\left(\frac{k}{k-1}\right)\left(1-\frac{\sum \sigma_{t}^{2}}{\sigma_{t}^{2}}\right)$

Dimana :

$r_{11}=$ Reliabilitas sangat rendah

$\sum \sigma_{t}^{2}=$ Jumlah varians skor tiap-tiap item

$\sigma_{t}^{2}=$ Varians total

Soal yang baik adalah soal yang tidak terlalu mudah atau tidak terlalu sukar. Untuk menentukan tingkat kesukaran tes atau indeks kesukaran tes dihitung dengan rumus ( Arikunto,2016 ).

$$
\mathrm{P}=\frac{B}{I S}
$$

Dengan :

$\mathrm{P} \quad=$ indeks kesukaran tes

B = banyaknya siswa yang menjawab soal yang benar

JS = Jumlah seluruh siswa peserta tes

Daya pembeda suatu soal dimaksudkan untuk dapat membedakan antara siswa yang pandai dan siswa yang kurang pandai. Sebuah soal dikatakan memiliki daya pembeda yang baik apabila siswa yang pandai dapat menjawab soal 
dengan baik, dan siswa yang kurang pandai tidak dapat menjawab soal dengan baik. Perhitungan daya pembeda setiap butir soal dilakukan dengan menggunakan rumus sebagai berikut:

$$
D=\frac{B_{A}}{J_{A}}-\frac{B_{B}}{J_{B}}=P_{A}-P_{B}
$$

Dengan :

$\mathrm{D}=$ Daya beda

$\mathrm{B}_{\mathrm{A}}=$ Banyaknya peserta kelompok atas yang menjawab soal dengan benar.

$\mathrm{B}_{\mathrm{B}}=$ Banyaknya peserta kelompok bawah yang menjawab soal dengan benar

$\mathrm{J}_{\mathrm{A}}=$ Banyaknya peserta kelompok atas

$\mathrm{J}_{\mathrm{B}}=$ Banyaknya peserta kelompok bawah

\section{HASIL dan PEMBAHASAN}

Data pretes kelas eksperimen dan kelas kontrol ditunjukkan pada Tabel 1 di bawah ini.

\section{Statistics}

Tabel 1. Nilai Pretes Kelas Kontrol

\begin{tabular}{|ll|r|}
\hline $\mathrm{N}$ & Valid & 30 \\
Mean & Missing & 0 \\
Std. Deviation & & 38,1397 \\
Variance & & 4,87250 \\
Range & & 23,741 \\
Minimum & 17,50 \\
Maximum & & 29,17 \\
\hline
\end{tabular}

Untuk kelas eksperimen, dapat dijabarkan melalui tabel 2 berikut

\section{Statistics}

Tabel 2. Nilai Pretes Kelas Eksperimen

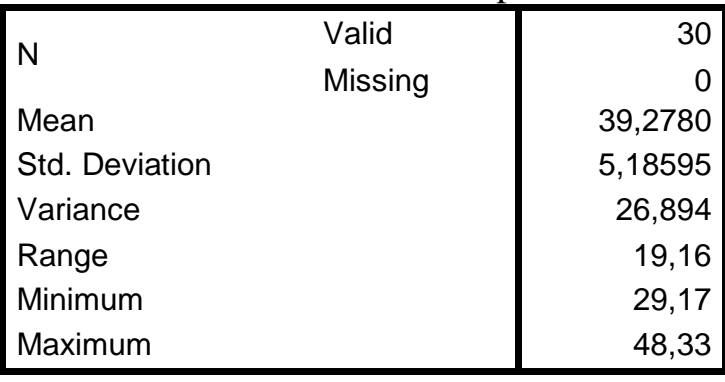

Dari hasil analisis diperoleh, bahwa harga sign (2-tiled) $=0,818$ dan $\alpha=0,05$, berarti data berditribusi normal. Untuk uji manual (uji Lilliefors), $\mathrm{L}_{\text {hitung }}=0,108$ dan Ltabel $=$ 0,161 pada $\alpha=0,05$ dan $n=30$ siswa, artinya secara uji Lilliefors (manual) data berdistribusi normal. Data pretes untuk kelas Eksperimen diperoleh nilai varians terbesar $\left(S_{1}{ }^{2}\right)=26,01$ dengan $\mathrm{n}=30$ sedangkan pada kelas Kontrol diperoleh nilai varians terkecil $\left(S_{2}{ }^{2}\right)=22,95$ dengan $\mathrm{n}=30$ dan nilai sign pada uji SPSS 20 yaitu 0,544 dan $\alpha=0,05$, Sehingga didapat disimpulkan data tersebut homogen. Dengan diperolehnya data siswa yang berdistribusi normal dan homogen dapat disimpulkan bahwa kemampuan awal siswa adalah sama.

Setelah diberikan perlakuan yang berbeda, kedua kelas diberikan postes untuk mengetahui hasil belajar siswa yang berupa pengetahuan konseptual. Adapun data postes dari kedua kelas dapat dilihat pada tabel di bawah ini.

\section{Statistics}

Tabel 3. Nilai Postes Kelas Kontrol

\begin{tabular}{|ll|r|}
\hline $\mathrm{N}$ & Valid & 30 \\
Mean & Missing & 0 \\
Std. Deviation & & 68,1380 \\
Variance & & 4,78285 \\
Range & 22,876 \\
Minimum & & 17,50 \\
Maximum & & 59,17 \\
\hline
\end{tabular}

Untuk kelas eksperimen dapat dilihat melalui tabel berikut ini

\section{Statistics}

Tabel 4. Nilai Postes Kelas Eksperimen

\begin{tabular}{|ll|r|}
\hline $\mathrm{N}$ & Valid & 30 \\
Mean & Missing & 0 \\
Std. Deviation & & 75,3620 \\
Variance & & 5,70201 \\
Range & 32,513 \\
Minimum & & 21,67 \\
Maximum & & 65,00 \\
\hline
\end{tabular}


Data postes di atas dilakukan pengujian hipotesis dengan uji t satu pihak. Setelah dilakukan postes, hasil pemberian postes untuk kelas eksperimen dan kelas kontrol diperoleh $\mathrm{t}_{\text {hitung }}=5,428$ sedangkan $\mathrm{t}_{\text {tabel }}=$ 1,671, karena $t_{\text {hitung }}>t_{\text {tabel }}$, dan menggunakan SPSS 20 terlihat bahwa harga sign $=0,401>\alpha=0,05$ maka dapat dikatakan bahwa Ada pengaruh yang signifikan Model Pembelajaran Problem Based Learning terhadap pengetahuan konseptual siswa pada materi pokok AlatAlat Optik

Penelitian ini diawali dengan pemberian pretes kepada kelas eksperimen dan kelas kontrol diperoleh nilai rata-rata pada kelas eksperimen adalah 44,87 sedangkan pada kelas kontrol adalah 43,91. Setelah diberi perlakuan yang berbeda, maka siswa diberi perlakuan postes dari hasil postes pada kelas eksperimen yang diterapkan dengan Model Pembelajaran Problem Based Learning diperoleh nilai rata-rata 74,27 sedangkan pada kelas kontrol yang menggunakan Model Pembelajaran Direct Instruction diperoleh nilai rata-rata 60,67 .

Dalam penelitian ini digunakan uji $\mathrm{t}$ satu pihak yang bertujuan untuk mengetahui adakah pengaruh yang signifikan penggunaan Model Pembelajaran Problem Based Learning terhadap pengetahuan konseptual fisika siswa. hasil pengujian hipotesis diperoleh $t_{\text {hitung }}(8,831)>t_{\text {tabel }}(2,002)$

\section{SIMPULAN}

Berdasarkan hasil pengolahan data dalam penelitian, maka dapat disimpulkan bahwa peningkatan pengetahuan konseptual siswa pada kelas eksperimen dengan menggunakan model problem based learning lebih baik dari kelas kontrol.

\section{DAFTAR PUSTAKA}

Amir, Taufiq, 2015. Inovasi Pendidikan Melalui Problem Based Learning. Jakarta: Prenada Media Group.
Arends, I. Richard, 2008. Learning To Teach, New York: Mc Graw Companies.

Joyce, Bruce, And Weil, M, 2016. Models Of Teaching. New Jersey : Pearson Education.

Novriyanti, Almira, 2014. Pengaruh Model Pembelajaran Berbasis Masalah Terhadap Hasil Belajar Siswa Pada Materi Pokok Suhu Dan Kalor Di Kelas X Semester II SMA Negeri 1 Delitua. Medan.

Rivai, Samsiar, 2014. Pengetahuan Konseptual Dan Prosedural Dalam Pembelajaran Perkalian Bilangan Pecah Desimal Berdasarkan Paham Konstruktivisme.

Rusman, 2014. Model-Model Pembelajaran Mengembangkan Profesionalisme Guru. Jakarta: Pt. Raja Grafindo Persada.

Subagya, Hari, 2013. Konsep Dan Penerapan Fisika SMA/MA Kelas $X$. Jakarta: Bumi Aksara. 